\title{
Prevalence and factors associated with sexual violence among rural women aged $15-49$ years in Uganda: evidence from the Uganda demographic and health survey 2016
}

\section{Joseph Kawuki ( $\nabla$ joseks256@gmail.com )}

Centre for Health Behaviours Research, Jockey Club School of Public Health and Primary Care, The Chinese University of Hong Kong, Hong Kong, CHINA. https://orcid.org/0000-0002-2440-1111

\section{Quraish Sserwanja}

Monitoring and Evaluation Department, Doctors with Africa, Juba, SOUTH SUDAN

\section{David Mukunya}

Department of Public Health, Busitema University, Tororo, UGANDA

\section{Abigail Sitsope Sepenu}

Department of Social Policy and Social Security Studies, Bonn-Rhein-Sieg University of Applied

Sciences, Bonn Germany.

\section{Milton Musaba}

Department of Obstetrics and Gynecology, Busitema University, Tororo, UGANDA

\section{Research Article}

Keywords: Sexual violence, Rural women, Gender-based violence, Risk factors, Uganda

Posted Date: November 6th, 2020

DOI: https://doi.org/10.21203/rs.3.rs-103249/v1

License: (9) This work is licensed under a Creative Commons Attribution 4.0 International License. Read Full License

Version of Record: A version of this preprint was published at Public Health on July 1st, 2021. See the published version at https://doi.org/10.1016/j.puhe.2021.05.004. 


\section{Abstract}

Background and Aim: Sexual violence is a serious global health problem with short and long-term physical, mental, and reproductive adverse-effects. We aimed to determine the prevalence and factors associated with sexual violence among rural women of reproductive age in Uganda.

Methods: We used the Uganda Demographic and Health Survey (UDHS) 2016 data for 5,259 rural women aged 15 to 49 years. Multi-stage stratified sampling was used to select respondents, and data were collected using validated questionnaires. We used multivariable logistic regression to determine factors associated with sexual violence. All analyses we carried out in SPSS (version 25).

Results: The overall prevalence of sexual violence was $24.3 \%$ (95\% Cl: 23.4-25.7), while that among pregnant women was $22.2 \%$ (95\% Cl: 19.1-25.6). Women of primary education had higher odds of sexual violence compared to those of tertiary education (AOR=3.01, 95\% $\mathrm{Cl}$ : 1.17-7.72), and those from the Western region compared to those in the Northern region (AORs $=2.01,95 \% \mathrm{Cl}$ : 1.41-2.87). Women of poorer wealth quintile also had higher odds of sexual violence compared to those of the richest quintile $(A O R=2.06,95 \% \mathrm{Cl}: 1.02-4.17)$. Higher odds of sexual violence were also found among women who justified beating ( $A O R=1.42,95 \% \mathrm{Cl}: 1.12-1.79)$, those who were not involved in healthcare decisionmaking (AOR=1.38, 95\% Cl: 1.01-1.91), and those whose husbands often got drunk (AOR=2.07, 95\% Cl: 1.30-3.31), compared to their counterparts.

Conclusions: The prevalence of sexual violence among rural women in Uganda was high and associated with factors such as education level, region, wealth index, justified beating, healthcare decision making, and husband drunk frequency. Thus, there is a need for improving livelihoods and income of rural women, promotion of girl-child education as well as strengthening protective laws and policies to curb this public health issue.

\section{Introduction}

Sexual violence (SV), a form of gender-based violence (GBV), is a serious global health issue that violates human rights [1]. Sexual violence has been defined as any sort of harmful or unwanted sexual behaviour that is imposed on someone [2]. The act is not only devastating for survivors and their families but also involves significant social and economic costs [1]. Intimate partners are often the perpetrators of this violence [2,3]. According to the World Health Organisation (WHO), GVB affects 1 in 3 women, and over $35 \%$ of women worldwide have experienced sexual and physical violence by either intimate partners or non-partners in their lifetime $[1,4]$.

A recent meta-analysis by Muluneh et al. reported the prevalence of sexual violence in sub-Saharan Africa to be $18.6 \%$, with the East African region having a higher prevalence compared to other regions [5]. A previous study indicated that $25 \%$ of the ever-married women in Uganda experienced some form of 
sexual violence [6]. Despite the presence of laws and policies to protect victims and survivors, GBV, including sexual violence, increased by 4\% between 2015 and 2016 in Uganda [7].

Sexual violence is known to have adverse physical, mental, and reproductive health outcomes to mothers and their children $[8,9]$. It also limits a woman's decision-making power regarding her reproductive health, putting her at risk for sexually transmitted infections (STIS) and unwanted pregnancies [10]. Sexual violence during pregnancy is associated with poor maternal and fetal outcomes, including miscarriages, low birth weight, preterm birth, and intrauterine growth restriction, among others $[9,11,12]$. In addition, children who witness violence have been reported to become future perpetrators of GBV [4]. Besides, several studies have reported several factors such as age, marital status, educational level, occupation, decision-making power, partners' alcohol intake and smoking, justified violence, among others to be associated with sexual violence $[10,13,14]$. Notably, an association has also been suggested between the area of residence (urban or rural) and sexual violence, and the same applies to social-economic status $[5,15]$.

To date, no comprehensive study has focused on exploring sexual violence in rural communities of Uganda. Residents of rural areas are usually faced with limited or no access to quality social and health care services. Given the devastating physical, mental and reproductive effects of sexual violence, it is essential to understand the various factors associated with this form of violence in the Ugandan context using nationally representative data. Identifying the risk factors of sexual violence among rural women is also vital in finding targeted, practical solutions as well as informing policy-makers. This study thus aimed to determine the prevalence and factors associated with sexual violence among rural women in Uganda, using data from the UDHS 2016.

\section{Methods}

\section{Study Data}

The study used secondary data of the 2016 UDHS collected from June 2016 to December 2016 in a nationally representative survey [16]. The survey (UDHS) was implemented by the Uganda Bureau of Statistics (UBOS) with the technical assistance of the Inner City Fund (ICF) International through the USAID-supported MEASURE DHS project [16]. The survey inquired about household members' and individual characteristics using a household questionnaire, while sexual violence data was collected by the woman's questionnaire, which included the domestic violence module [16].

\section{Study setting}

As of July 2018 , Uganda had a population of approximately 41 million people with $76.2 \%$ of the population residing in rural areas [17], and the country has $21.4 \%$ of the population living below the poverty line [18]. The average female expected years of schooling are 10.4, with the actual mean of 4.8 female years of schooling. The average age at first marriage and females' birth in the country are 18.2 and 18.9 years, respectively [18]. The country's family setting rotates on the husband, who is regarded as 
the family head [18]. Uganda has a six-level health system that ranges from the national referral hospitals, as the highest level, to community-level health centres [19]. Agriculture is the primary source of income for Ugandans, and it contributes about $50 \%$ of export earnings [18].

\section{Study sampling and participants}

UDHS employed a two-stage cluster sampling technique, where the census enumeration areas were the primary sampling units, and households were the secondary sampling units [16]. The enumeration areas were selected from the 2014 population and housing census sample frame [16]. A total of 18,506 women aged 15-49 years participated in the UDHS 2016, of which 9,232 women were sampled to respond to the domestic violence questions, and of these, 5,259 women resided in rural areas. One per cent (1\%) of eligible women could not be successfully interviewed with the module because of the lack of privacy or other reasons. Weights were used to adjust for the selection of only one person per household and to ensure that the domestic violence subsample was nationally representative [16].

\section{Variables}

\section{Dependent variable}

The dependent variable in this study was the history of exposure to sexual violence among rural women in Uganda. During the survey, rural women were asked about their experience of any form of sexual violence at any time in their life, as a child or as an adult [16].

\section{Independent variables}

This study included determinants of sexual violence based on evidence from the available literature $[13,14]$. These included; individual level (age, pregnancy status, working status, justified beating, parity and educational level), household level (household size, husband's educational level, wealth index, healthcare decision-making, husbands age, and drinking frequency as well as husbands working status) and community level (region) factors. Wealth index is a measure of relative household economic status and was calculated by UDHS from information on household asset ownership using principal component analysis [16]. These quintiles were; the poorest, the poorer, the middle, the richer, and the richest quintiles [16]. Healthcare decision-making was classified as "woman alone," "with someone," or "not involved." Besides, "region" was categorised into four; Northern, Central, Eastern, and Western [20]. Level of Education was classified as no education, primary education, secondary and tertiary education. Age was categorised into 20-29, 30-39, and 40-49. Parity was classified as "less than 4" and "above 4", household size as " 5 and below" and "above 5 ", while drunk frequency was categorised into three; never, sometimes, and often.

\section{Statistical analysis}

Statistical analysis was performed using SPSS complex samples software (version 25.0), which accounted for the multi-stage cluster study design. We used weighted counts in the analysis to account 
for the unequal probability sampling in different strata [21] and to ensure the representativeness of the survey results at the national and regional levels. We summarised selected categorical variables as frequencies and proportions.

Factors known to be associated with sexual violence, from the literature, were evaluated and those found significant at a p-value less than 0.2 at bivariable analysis [22] were included in the multivariable models. We presented two models; the primary model, which adjusted for only factors without missing data, and the secondary model, which included all the factors (with and without missing data) and adjusted for those with missing data. The crude odds ratio (COR), adjusted odds ratios (AOR), 95\% Confidence Intervals $(\mathrm{Cl})$, and $\mathrm{p}$-values were reported. The statistical significance level was set at $\mathrm{p}$-value $<0.05$ for multivariable logistic regression analysis. We assessed all covariates for collinearity, using a cut off value of above 10 variance inflation factor [23].

\section{Results}

A total of 5259 rural women were included in this study, and the prevalence of sexual violence was $24.3 \%$ (95\% Cl: 23.4-25.7) (Table 1). Of the participants, 675 were pregnant, with a prevalence of sexual abuse of $22.2 \%$ (95\% Cl: 19.1-25.6). Majority of the women were below 35 years $(64.2 \%)$ and not pregnant (87.2\%). $60.1 \%$ were from Western and Eastern Uganda, $83.3 \%$ were working, $49 \%$ had husbands with primary education as the highest level of education, and $60.7 \%$ took health care decisions alone or with someone. The majority (65.8\%) had primary education as their highest level of education, and $71.5 \%$ belonged to the middle or a less wealth index, while $57 \%$ had a parity of less than $4,78 \%$ justified beating, and $50.6 \%$ had household size of above 5 . In addition, $40.9 \%$ had husbands who often or sometimes get drunk, $62.6 \%$ had husbands less than 45 years of age, and $80.4 \%$ had employed/ working husbands. The details are in Table 1.

\section{Factors associated with sexual violence}

Bivariable analysis results are shown in Table 2. In the primary logistic regression model, factors associated with sexual violence were: region, working status, justified beating, and household size. After adjusting for factors with missing data, the secondary model showed educational level, region, wealth index, justified beating, healthcare decision making, and husband drinking frequency as the significant factors associated with sexual violence (Table 3 ).

Compared to those of tertiary educational level, women of primary $(3.01,95 \% \mathrm{Cl}: 1.17-7.72)$ and secondary $(2.74,95 \% \mathrm{Cl}: 1.06-7.07)$ levels were $201 \%$ and $174 \%$, respectively, more likely to experience sexual violence. Compared to the Northern region, women from the Western (AOR=2.01, 95\% Cl: 1.41 2.87) and Eastern (AOR=1.91, 95\% Cl: $1.35-2.72)$ regions of Uganda were $101 \%$ and $91 \%$ more likely to experience sexual violence, respectively. Compared to those from the richest wealth index, women from the richer (AOR=2.90, 95\% Cl: 1.41-5.99) and poorer ( $A O R=2.06,95 \% \mathrm{Cl}: 1.02-4.17)$ wealth indexes were more $190 \%$ and $106 \%$ likely to experience sexual violence, respectively. Women who justified beating were $42 \%$ more likely to experience sexual violence ( $A O R=1.42,95 \% \mathrm{Cl}: 1.12-1.79)$ compared to those who did 
not. Women who were not involved in making healthcare decisions had a 38\% increased chances of experiencing sexual violence, with $\mathrm{AOR}=1.38$ (95\% $\mathrm{Cl}: 1.01-1.91)$, compared to those making healthcare decisions alone. Notably, women whose husbands often got drunk had $107 \%$ additional chances of being sexually abused compared to those whose husbands never got drunk, AOR=2.07 ( $95 \% \mathrm{Cl}$ : 1.30-3.31), as shown in Table 3.

\section{Discussion}

This study examined the prevalence and factors associated with sexual violence among Ugandan rural women of reproductive age. The prevalence of sexual violence among our participants was $24.3 \%$. This prevalence is slightly higher than the national prevalence of $22 \%$ [16]. Rural settings have been linked with higher rates of physical and sexual violence than urban areas, which can be attributed to the difference in the social-dynamics that increase chances of domestic violence in rural areas [10,24,25]. Compared to urban settings, the strong cultural believes, ties and norms, as well as higher poverty levels in rural areas, could explain the higher prevalence of sexual violence $[6,10,25]$.

The study identified several factors that were significantly associated with sexual violence, including women's educational level, region, wealth index, justified beating, healthcare decision-making, and husband drinking frequency.

Women with a tertiary educational level and richest wealth quintile were less likely to experience sexual violence than the less educated and poor ones. Higher (post-secondary) level of education implies more awareness about individual rights, and educated women are more financially stable and more empowered compared to the poor less educated [15]. The results agree with previous studies that also reported higher educational level and richest wealth quintile as protective factors against not only sexual violence but also gender inequality $[6,15,26]$. This implies that more efforts and targeted interventions are needed to improve the livelihoods of rural women to reduce financial dependence on their husbands. In addition, promotion of girl-child education is a vital tool for women empowerment, improving the social status and reducing gender-based violence.

Women from Western and Eastern Uganda had the highest chances of having experienced sexual violence, compared to those in the Northern region. The findings are in line with Wandera et al., who reported the highest rate of sexual violence in the Eastern region, followed by Western, Central, and Northern regions [6]. However, the results deviate from a recent meta-analysis that reported Northern Uganda having the highest rate of sexual violence (50\%) within Sub-Saharan Africa [5]. Although the Northern region has a record of past civil wars that were characterised by the violation of human rights, including sexual abuse [27], our study found no significant chances of sexual violence among women in this region. The reasons underlying the higher risks of sexual violence in the Western and Eastern regions of the country are not clear, calling for further investigation. However, the higher sexual violence risks in these regions may be linked to social-cultural norms such as women subordinate, justified violence, among others $[28,29]$. 
In addition, women who justified beating showed higher odds of sexual violence, unlike their counterparts. The results agree with previous studies that highlight justified violence as a risk factor for sexual violence $[28,29]$. Strict adherence to cultural norms that emphasise women's inferiority to men or those which objectify women affects the mindset and awareness of women about their rights [29]. Justified violence against women is deeply rooted in cultural norms and practices like payment of bride price, grooming women to be submissive and subservient, among others. All these disempower women from taking part in sexual decision-making while mounting men with infinite sexual contact with their wives [28]. Therefore, there is a need for culture-oriented sensitisation programs to condemn negative cultural norms and practices that violet women's rights.

The study also noted that women who were involved in healthcare decision-making had lower chances of experiencing sexual violence compared to those who did not. The ability to make independent healthcare decisions imply knowledge of one's rights, as well as empowerment. Women who do not take part, at all, in their healthcare decision making are more likely to be less empowered and so are prone to not only sexual violence but also physical violence [25]. In addition, joint decision making (wife and husband) could imply better communication and fewer incidences of misunderstandings, thus less chances of sexual violence in a home. The results agree with Semahegn's study [30], which also indicated joint decision-making as a protective factor against not only sexual violence but also other forms of domestic violence.

The study revealed that women with husbands who often get drunk were more likely to be sexually abused compared to those whose husbands don't get drunk. The results agree with previous studies that also highlighted the husband's behaviour like alcohol consumption as a risk factor for not only sexual violence but also physical violence [6,28]. Excessive alcohol consumption has been linked with aggressive behaviour and increases the chances of misunderstandings and conflict among partners leading to sexual violence, especially when the woman does not drink [28].

Notably, although it became non-significant on controlling for missing data, working status also had some association with sexual violence. Employed women showed higher odds of sexual violence compared to the unemployed ones. This finding is similar to other studies that have also reported working women having more chances of being sexually abused $[25,31,32]$. Although employment directly translates to women empowerment [26], it has been shown, in several studies, not to be a protective factor against sexual violence among women $[25,32,33]$. This could be due to the work-related sexual abuse faced by women, depending on the type of employment, especially in the informal sector. For example, some studies have also reported higher rates of sexual violence among female sex workers as well as casual labourers $[34,35,36]$. This implies a need to strengthen the country's available protective policies to ensure the safety of working women.

\section{Strengths and Limitations of the study}

Standardised procedures are a requirement of DHS surveys in data collection, and validated questionnaires are used, which ensures the internal and external validity of the results. Secondly, we used 
the most recent nationally representative sample and weighed the data for analysis, and therefore, our results are generalised to all Ugandan women aged 15 to 49 years.

However, the study had some limitations, such as the possibility of information bias, as well as recall, and interviewer biases since most data on the predictors were based on self-reporting, which could not be verified through records, and respondents gave answers about events that occurred in the past. In addition, data on explanatory variables such as wealth and working status reflected the women's conditions at the time of the survey and not at the time experiencing sexual violence. Hence, women may have moved from one category of classification into another. Such non-differential misclassification may have reduced the strengths of observed associations.

\section{Conclusions}

The study has found a considerable prevalence of sexual violence among rural Ugandan women of reproductive age. Several factors have also been found to be associated with sexual violence among these people, including educational level, region, wealth index, justified beating, healthcare decision making, husband drunk frequency, and working status. Thus, the study results indicate a need for strategies aimed at improving rural women's livelihoods and income, as well as promoting education of the girl-child as a tool for women empowerment and protection against not only sexual violence but also gender-based inequalities. Culturally-oriented community sensitisation programs and strengthening protective laws and policies against sexual violence are also key in addressing this public health problem in Uganda.

\section{Declarations}

\section{Author contributions}

QS and JK initiated the topic, analyzed the data and wrote the first draft of the paper. DM, ASS and MM made critical input and comments on the draft manuscript. QS and DM contributed to the interpretation and writing of the paper. All authors read and approved the final manuscript.

\section{Acknowledgments}

We acknowledge the participants of the 2016 UDHS as well as the DHS program for providing us with the survey data for these analyses.

\section{Funding}

None

\section{Conflict of interest}


The authors declare that they have no known competing financial interests or personal relationships that could have appeared to influence the work reported in this paper.

\section{Consent to participate and Ethical considerations}

Participants' consent was sought prior the UDHS and no identifying information was disclosed.

\section{References}

1. The World Bank. September 2019. Gender-Based Violence (Violence Against Women and Girls). Available at: https://www.worldbank.org/en/topic/socialdevelopment/brief/violence-against-womenand-girls. Accessed $28^{\text {th }}$ July 2020.

2. United Nations, 2015. The World's Women 2015: Trends and Statistics. New York: United Nations, Department of Economic and Social Affairs, Statistics Division.

3. World Health Organization. Global and regional estimates of violence against women: prevalence and health effects of intimate partner violence and non-partner sexual violence. World Health Organization. 2013. Geneva. 51pp.

4. World Health Organisation. November 2017. Violence against women. Available at: https://www.who.int/en/news-room/fact-sheets/detail/violence-against-women. Accessed $28^{\text {th }}$ July 2020.

5. Muluneh MD, Stulz V, Francis L, Agho K. Gender based violence against women in sub-Saharan Africa: a systematic review and meta-analysis of cross-sectional studies. International journal of environmental research and public health. 2020 Jan;17(3):903.

6. Wandera SO, Ntozi JP, Kwagala B. Spousal sexual violence, sexual behavior and sexually transmitted infections among ever-married women in Uganda. African Population Studies. 2010;24(1-2).

7. Ssenkaaba S. Uganda: Violence against women unabated despite laws and policies. United Nations African Renewal, 2018.Available at: https://www.un.org/africarenewal/news/uganda-violenceagainst-women-unabated-despite-laws-and-policies. Accessed $30^{\text {th }}$ July 2020.

8. Orpin J, Papadopoulos C, Puthussery S. The prevalence of domestic violence among pregnant women in Nigeria: a systematic review. Trauma, Violence, \& Abuse. 2020 Jan;21(1):3-15.

9. Hill A, Pallitto C, McCleary-Sills J, Garcia-Moreno C. A systematic review and meta-analysis of intimate partner violence during pregnancy and selected birth outcomes. International Journal of Gynecology \& Obstetrics. 2016 1st June;133(3):269-76.

10. Semahegn A, Mengistie B. Domestic violence against women and associated factors in Ethiopia; systematic review. Reproductive health. 2015 Dec 1;12(1):78.

11. Do HP, Tran BX, Nguyen CT, Van Vo T, Baker PR, Dunne MP. Inter-partner violence during pregnancy, maternal mental health and birth outcomes in Vietnam: A systematic review. Children and Youth Services Review. 2019 1st January;96:255-65. 
12. Boy A, Salihu HM. Intimate partner violence and birth outcomes: a systematic review. International journal of fertility and women's medicine. 2004 1st July;49(4):159-64.

13. Oladepo $O$, Yusuf OB, Arulogun OS. Factors influencing gender based violence among men and women in selected states in Nigeria. African journal of reproductive health. 2011;15(4):78-86.

14. Arnold D, Gelaye B, Goshu M, Berhane Y, Williams MA. Prevalence and risk factors of gender-based violence among female college students in Awassa, Ethiopia. Violence and Victims. 2008 Dec $1 ; 23(6): 787-800$.

15. García-Moreno C, Jansen HA, Ellsberg M, Heise L, Watts C. WHO multi-country study on women's health and domestic violence against women. Geneva: World Health Organization. 2005 Nov;204:1-8.

16. ICF, UBOS. Uganda demographic and health survey 2016. Kampala, Uganda: UBOS and ICF. 2018.

17. Richmond A, Myers I, Namuli H. Urban Informality and Vulnerability: A Case Study in Kampala, Uganda. Urban Science. 2018;2(1).

18. Central Intelligence Agency: The World Fact Book: Uganda. January 2019. Available at: cia.gov/library/publications/the-world-factbook/geos/ug. Accessed $3^{\text {rd }}$ August 2020.

19. Benova L, Dennis ML, Lange IL, Campbell OMR, Waiswa P, Haemmerli M, et al. Two decades of antenatal and delivery care in Uganda: a cross-sectional study using Demographic and Health Surveys. BMC health services research. 2018;18(1):758-.

20. Yang YY, Kaddu G, Ngendahimana D, Barkoukis H, Freedman D, Lubaale YA, et al. Trends and determinants of stunting among under-5s: evidence from the 1995, 2001, 2006 and 2011 Uganda Demographic and Health Surveys. Public health nutrition. 2018;21(16):2915-28.

21. Abrha S, Shiferaw S, Ahmed KY. Overweight and obesity and its socio-demographic correlates among urban Ethiopian women: evidence from the 2011 EDHS. BMC Public Health. 2016;16:636.

22. Lee PH, Burstyn I. Identification of confounder in epidemiologic data contaminated by measurement error in covariates. BMC medical research methodology. 2016;16:54-.

23. Midi H, Sarkar SK, Rana S. Collinearity diagnostics of binary logistic regression model. Journal of Interdisciplinary Mathematics. 2010;13(3):253-67.

24. Sendo EG, Meleku M (2015) Prevalence and factors associated with sexual violence among female students of Hawassa University in Ethiopia. Science Postprint 1(2): e00047.

10.14340/spp.2015.04A0002.

25. Dalal K, Lindqvist K. A national study of the prevalence and correlates of domestic violence among women in India. Asia Pacific Journal of Public Health. 2012 Mar;24(2):265-77.

26. Abeya SG, Afework MF, Yalew AW. Intimate partner violence against women in western Ethiopia: prevalence, patterns, and associated factors. BMC public health. $2011 \mathrm{Dec}$ 1;11(1):913.

27. Amone-P'Olak K. Psychological impact of war and sexual abuse on adolescent girls in Northern Uganda. Intervention. 2005 Mar;3(1):33-45.

28. Apatinga GA, Tenkorang EY. Determinants of sexual violence against married women: qualitative evidence from Ghana. Sexual Abuse. 2020 Mar 1:1079063220910728. 
29. Koenig MA, Lutalo T, Zhao F, Nalugoda F, Wabwire-Mangen F, Kiwanuka N, Wagman J, Serwadda D, Wawer M, Gray R. Domestic violence in rural Uganda: evidence from a community-based study. Bulletin of the world health organisation. 2003;81:53-60.

30. Semahegn A, Belachew T, Abdulahi M. Domestic violence and its predictors among married women in reproductive age in Fagitalekoma Woreda, Awi zone, Amhara regional state, North Western Ethiopia. Reproductive health. 2013 Dec 1;10(1):63.

31. Chikhungu LC, Amos M, Kandala N, Palikadavath S. Married women's experience of domestic violence in Malawi: New evidence from a cluster and multinomial logistic regression analysis. Journal of interpersonal violence. 2019 Jun 3:0886260519851782.

32. Mahenge B, Stöckl H, Abubakari A, Mbwambo J, Jahn A. Physical, sexual, emotional and economic intimate partner violence and controlling behaviors during pregnancy and postpartum among women in Dar es Salaam, Tanzania. PloS one. 2016 Oct 18;11(10):e0164376.

33. Deribe K, Beyene BK, Tolla A, Memiah P, Biadgilign S, Amberbir A. Magnitude and correlates of intimate partner violence against women and its outcome in Southwest Ethiopia. PloS one. $2012 \mathrm{Apr}$ 25;7(4):e36189.

34. Alemayehu M, Yohannes G, Damte A, Fantahun A, Gebrekirstos K, Tsegay R, Goldberger A, Yebyo H. Prevalence and predictors of sexual violence among commercial sex workers in Northern Ethiopia. Reproductive health. 2015 Dec;12(1):1-7.

35. Go VF, Srikrishnan AK, Parker CB, Salter M, Green AM, Sivaram S, Johnson SC, Latkin C, Davis W, Solomon S, Celentano DD. High prevalence of forced sex among non-brothel based, wine shop centered sex workers in Chennai, India. AIDS and Behavior. 2011 1st January;15(1):163-71.

36. Decker MR, McCauley HL, Phuengsamran D, Janyam S, Seage GR, Silverman JG. Violence victimisation, sexual risk and sexually transmitted infection symptoms among female sex workers in Thailand. Sexually transmitted infections. 2010 1st June;86(3):236-40.

\section{Tables}

Table 1. Background characteristics of rural Ugandan women as per the 2016 UDHS 


\begin{tabular}{|c|c|c|}
\hline Characteristics & $\mathrm{N}=5259$ & $\%$ \\
\hline \multicolumn{3}{|l|}{ Age } \\
\hline $15-24$ & 1522 & 28.9 \\
\hline $25-34$ & 1858 & 35.3 \\
\hline $39-49$ & 1880 & 35.7 \\
\hline \multicolumn{3}{|l|}{ Pregnant } \\
\hline No & 4584 & 87.2 \\
\hline Yes & 675 & 12.8 \\
\hline \multicolumn{3}{|l|}{ Region } \\
\hline Western & 1387 & 26.4 \\
\hline Eastern & 1584 & 30.1 \\
\hline Central & 1096 & 20.8 \\
\hline Northern & 1193 & 22.7 \\
\hline \multicolumn{3}{|l|}{ Working status } \\
\hline No & 876 & 16.7 \\
\hline Yes & 4383 & 83.3 \\
\hline \multicolumn{3}{|c|}{ Husbands Educational level a } \\
\hline No education & 315 & 6.0 \\
\hline Primary & 2579 & 49.0 \\
\hline secondary & 1045 & 19.9 \\
\hline Tertiary & 370 & 7.0 \\
\hline \multicolumn{3}{|c|}{ Healthcare Decision Making ${ }^{\text {b }}$} \\
\hline Not involved & 1187 & 22.6 \\
\hline With someone & 1901 & 36.1 \\
\hline Alone & 1293 & 24.6 \\
\hline \multicolumn{3}{|c|}{ Educational level } \\
\hline No education & 751 & 14.3 \\
\hline Primary & 3461 & 65.8 \\
\hline Secondary & 816 & 15.5 \\
\hline
\end{tabular}




\begin{tabular}{|c|c|c|}
\hline Tertiary & 232 & 4.4 \\
\hline \multicolumn{3}{|c|}{ Wealth index } \\
\hline Poorest & 1228 & 23.4 \\
\hline Poorer & 1312 & 24.9 \\
\hline Middle & 1220 & 23.2 \\
\hline Richer & 1009 & 19.2 \\
\hline Richest & 490 & 9.3 \\
\hline \multicolumn{3}{|c|}{ Sexual violence } \\
\hline Yes & 1278 & 24.3 \\
\hline No & 3981 & 75.7 \\
\hline \multicolumn{3}{|l|}{ Parity } \\
\hline Above 4 & 2261 & 43.0 \\
\hline Below 4 & 2998 & 57.0 \\
\hline \multicolumn{3}{|c|}{ Justified beating ${ }^{c}$} \\
\hline Yes & 1130 & 78.0 \\
\hline No & 4104 & 21.5 \\
\hline \multicolumn{3}{|c|}{ Household size } \\
\hline Above 5 & 2660 & 50.6 \\
\hline Below 5 & 2599 & 49.4 \\
\hline \multicolumn{3}{|c|}{ Husband Drunk Frequency d } \\
\hline Often & 889 & 16.9 \\
\hline Sometimes & 1262 & 24.0 \\
\hline Never & 214 & 4.1 \\
\hline \multicolumn{3}{|c|}{ Husband/Partner Age ${ }^{e}$} \\
\hline $15-24$ & 494 & 9.4 \\
\hline $25-34$ & 1500 & 28.5 \\
\hline $35-44$ & 1301 & 24.7 \\
\hline Above 44 & 1086 & 20.6 \\
\hline
\end{tabular}




\begin{tabular}{|lll|}
\hline Yes & 4227 & 80.4 \\
\hline No & 147 & \\
\hline
\end{tabular}

${ }^{a}$ Missing 950, ${ }^{b}$ Missing $878,{ }^{c}$ Missing 26, ${ }^{d}$ Missing $2895,{ }^{e}$ Missing $878,{ }^{f}$ Missing 885

Table 2: Bivariable analysis of determinants of sexual violence among Ugandan rural women 


\begin{tabular}{|c|c|c|c|}
\hline Characteristics & $\begin{array}{l}\text { Experienced sexual violence } \\
(n=1278)\end{array}$ & $\begin{array}{l}\text { Didn't experience sexual violence } \\
(\mathrm{n}=3981)\end{array}$ & P-Value \\
\hline Working status & & & $<0.001 *$ \\
\hline No & $171(13.4)$ & 705 (17.7) & \\
\hline Yes & 1106(86.6) & 3277 (82.3) & \\
\hline Wealth Index & & & $<0.001 *$ \\
\hline Poorest & $286(22.4)$ & $942(23.7)$ & \\
\hline Poorer & 347 (27.2) & 965 (24.2) & \\
\hline Middle & $313(24.5)$ & $906(22.8)$ & \\
\hline Richer & 254 (19.9) & $756(19.0)$ & \\
\hline Richest & $78(6.1)$ & $412(10.3)$ & \\
\hline Education Level & & & $<0.001 *$ \\
\hline No Education & $162(12.7)$ & $589(14.8)$ & \\
\hline Primary & 918 (71.8) & $2543(63.9)$ & \\
\hline Secondary & $166(13.0)$ & $650(16.3)$ & \\
\hline Tertiary & $32(2.5)$ & $200(5.0)$ & \\
\hline Region & & & $<0.001 *$ \\
\hline West & 360 (28.2) & $1027(25.8)$ & \\
\hline Eastern & $475(37.2)$ & $1108(27.8)$ & \\
\hline Central & $219(17.1)$ & $877(22.0)$ & \\
\hline Northern & $223(17.5)$ & $970(24.4)$ & \\
\hline Health Decision & & & $<0.001 *$ \\
\hline Not Involved & 333 (33.7) & $854(25.2)$ & \\
\hline With Someone & $347(35.1)$ & $1554(45.8)$ & \\
\hline Alone & 309 (31.2) & $985(29.0)$ & \\
\hline Age & & & $0.024^{*}$ \\
\hline 15 to 24 & $338(26.4)$ & $1184(29.7)$ & \\
\hline 25 to 34 & $447(35.0)$ & 1411 (35.4) & \\
\hline 35 to 49 & $493(38.6)$ & 1387 (34.8) & \\
\hline Pregnant & & & $0.181 *$ \\
\hline
\end{tabular}




\begin{tabular}{|c|c|c|c|}
\hline No & 1127(88.3) & 3457 (86.8) & \\
\hline Yes & $150(11.7)$ & $525(13.2)$ & \\
\hline $\begin{array}{l}\text { Husband } \\
\text { Education }\end{array}$ & & & $0.001 *$ \\
\hline No & $70(7.2)$ & $245(7.4)$ & \\
\hline Primary & $634(64.8)$ & $1945(58.4)$ & \\
\hline Secondary & $216(22.1)$ & $829(24.9)$ & \\
\hline Tertiary & $59(6.0)$ & $312(9.4)$ & \\
\hline Parity & & & $<0.001 *$ \\
\hline Above 4 & $612(47.9)$ & $1649(44.4)$ & \\
\hline Less than 4 & $666(52.1)$ & $2333(58.6)$ & \\
\hline Justified Beating & & & $<0.001 *$ \\
\hline Yes & $356(28.0)$ & 774 (19.5) & \\
\hline No & $914(72.0)$ & $3191(80.5)$ & \\
\hline Household Size & & & $0.002^{*}$ \\
\hline Above 5 & $706(55.2)$ & $1954(49.1)$ & \\
\hline 5 and Below & $572(44.8)$ & $2027(50.9)$ & \\
\hline Husband & & & $0.101 *$ \\
\hline (anding & $962(97.5)$ & $3265(96.4)$ & \\
\hline 10 & $25(2.5)$ & $122(3.6)$ & \\
\hline & & & \\
\hline Husband Drunk & & & $<0.001 *$ \\
\hline Often & $332(47.8)$ & $556(33.3)$ & \\
\hline Sometimes & $321(46.2)$ & $941(56.4)$ & \\
\hline Never & $42 \quad(6.0)$ & $172(10.3)$ & \\
\hline $\begin{array}{l}\text { Husband/Partner } \\
\text { Age }\end{array}$ & & & $0.151^{*}$ \\
\hline $15-24$ & $101(10.2)$ & $393(11.6)$ & \\
\hline $25-34$ & $313(31.7)$ & 1187(35.0) & \\
\hline $35-44$ & $306(31.0)$ & $995(29.3)$ & \\
\hline & $268(27.1)$ & $818(24.1)$ & \\
\hline
\end{tabular}


*= Significant at $p$-value $<0.20$

Table 3: Multivariable analysis of determinants of determinants of sexual violence among Ugandan rural women aged 15-49 years 


\begin{tabular}{|c|c|c|c|}
\hline \multirow[t]{2}{*}{ Characteristics } & $\begin{array}{l}\text { Crude model } \\
(n=5259)\end{array}$ & $\begin{array}{l}\text { Primary Adjusted model } \\
(n=5259)\end{array}$ & $\begin{array}{l}\text { Secondary } \\
\text { Model }\end{array}$ \\
\hline & $\operatorname{COR}(95 \% \mathrm{Cl})$ & AOR $(95 \% \mathrm{Cl})$ & AOR $(95 \% \mathrm{Cl})$ \\
\hline \multicolumn{4}{|l|}{ Age } \\
\hline 35 to 49 & 1 & 1 & 1 \\
\hline 25 to 34 & $0.89(0.76-1.05)$ & $0.89(0.69-1.15)$ & $\begin{array}{l}1.08(0.77- \\
1.53)\end{array}$ \\
\hline 15 to 24 & $0.80(0.66-0.98)$ & $0.95(0.79-1.14)$ & $\begin{array}{l}0.86(0.53- \\
1.40)\end{array}$ \\
\hline \multicolumn{4}{|l|}{ Education Level } \\
\hline Tertiary & 1 & 1 & 1 \\
\hline Secondary & $1.60(0.89-2.86)$ & $1.31(0.72-2.41)$ & $\begin{array}{l}2.74(1.06- \\
7.07)\end{array}$ \\
\hline Primary & $2.26(1.29-3.94)$ & $1.64(0.89-3.01)$ & $\begin{array}{l}3.01(1.17- \\
7.72)\end{array}$ \\
\hline No Education & $1.72(0.96-3.06)$ & $1.22(0.65-2.29)$ & $\begin{array}{l}2.47(0.90- \\
6.80)\end{array}$ \\
\hline \multicolumn{4}{|l|}{ Region } \\
\hline Northern & 1 & 1 & 1 \\
\hline Eastern & $1.86(1.45-2.39)$ & $1.95(1.52-2.51)$ & $\begin{array}{l}1.91(1.35- \\
2.72)\end{array}$ \\
\hline Western & $1.52(1.20-1.93)$ & $1.69(1.29-2.22)$ & $\begin{array}{l}2.01 \\
2.87)\end{array}$ \\
\hline Central & $1.08(0.84-1.41)$ & $1.26(0.95-1.68)$ & $\begin{array}{l}1.26(0.78- \\
2.03)\end{array}$ \\
\hline \multicolumn{4}{|l|}{ Pregnant } \\
\hline Yes & 1 & 1 & 1 \\
\hline No & $1.14(0.91-1.43)$ & $1.09(0.86-1.38)$ & $\begin{array}{l}1.08(0.79- \\
1.49)\end{array}$ \\
\hline \multicolumn{4}{|l|}{ Wealth Index } \\
\hline Richest & 1 & 1 & 1 \\
\hline Richer & $1.78(1.19-2.66)$ & $1.46(0.98-2.18)$ & $\begin{array}{l}2.90(1.41- \\
5.99)\end{array}$ \\
\hline Middle & $1.84(1.22-2.77)$ & $1.37(0.90-2.10)$ & $\begin{array}{l}1.63(0.79- \\
3.38)\end{array}$ \\
\hline
\end{tabular}




\begin{tabular}{|c|c|c|c|}
\hline Poorer & $1.91(1.29-2.81)$ & $1.47(0.98-2.21)$ & $\begin{array}{l}2.06(1.02- \\
4.17)\end{array}$ \\
\hline Poorest & $1.62(1.09-2.38)$ & $1.42(0.93-2.17)$ & $\begin{array}{l}1.71(0.81- \\
3.61)\end{array}$ \\
\hline \multicolumn{4}{|c|}{ Husband Education } \\
\hline Tertiary & 1 & & 1 \\
\hline Secondary & $1.38(0.97-1.98)$ & & \multirow{2}{*}{$\begin{array}{l}1.05(0.63- \\
1.77)\end{array}$} \\
\hline Primary & $1.73(1.21-2.46)$ & & \\
\hline \multirow{2}{*}{ No Education } & $1.50(0.95-2.37)$ & & $\begin{array}{l}0.90(0.55- \\
1.47)\end{array}$ \\
\hline & & & $\begin{array}{l}0.79(0.41- \\
1.51)\end{array}$ \\
\hline \multicolumn{4}{|l|}{ Working status } \\
\hline No & 1 & 1 & 1 \\
\hline Yes & $1.39(1.10-1.75)$ & $1.35(1.06-1.73)$ & $\begin{array}{l}1.16(0.78- \\
1.71)\end{array}$ \\
\hline \multicolumn{4}{|l|}{ Parity } \\
\hline Less than 4 & 1 & 1 & 1 \\
\hline Above 4 & $1.30(1.13-1.50)$ & $1.08(0.88-1.32)$ & $\begin{array}{l}1.00(0.72- \\
1.39)\end{array}$ \\
\hline \multicolumn{4}{|c|}{ Justified Beating } \\
\hline No & 1 & 1 & 1 \\
\hline Yes & $1.60(1.37-1.88)$ & $1.58(1.35-1.86)$ & $\begin{array}{l}1.42(1.12- \\
1.79)\end{array}$ \\
\hline \multicolumn{4}{|c|}{ Household Size } \\
\hline 5 and Below & 1 & 1 & 1 \\
\hline Above 5 & $1.28(1.09-1.49)$ & $1.20(1.01-1.43)$ & $\begin{array}{l}1.01(0.77- \\
1.31)^{(1.0}\end{array}$ \\
\hline \multicolumn{4}{|c|}{ Husband Working } \\
\hline Yes & 1 & & 1 \\
\hline No & $0.69(0.46-1.03)$ & & $\begin{array}{l}0.91(0.53- \\
1.55)\end{array}$ \\
\hline \multicolumn{4}{|c|}{$\begin{array}{l}\text { Healthcare Decision } \\
\text { making }\end{array}$} \\
\hline Woman Alone & 1 & & 1 \\
\hline
\end{tabular}




\begin{tabular}{|lll|} 
With Someone & $\mathbf{0 . 7 1}(\mathbf{0 . 5 8 - 0 . 8 7 )}$ & $0.81(0.61-$ \\
Not Involved & $\mathbf{1 . 2 5 ( 1 . 0 1 - 1 . 5 4 )}$ & $1.07)$ \\
& & $\mathbf{1 . 3 8}(\mathbf{1 . 0 1 -}$ \\
Drunk Frequency & & $\mathbf{1 . 9 1 )}$ \\
Never & 1 & $\mathbf{1}$ \\
Sometimes & $1.40(0.94-2.07)$ & $1.34(0.85-2.12)$ \\
Often & $\mathbf{2 . 4 4 ( 1 . 6 5 - 3 . 6 0 )}$ & $\mathbf{2 . 0 7}(1.30-$ \\
Partner Age & & $\mathbf{3 . 3 1})$ \\
Above 44 & $\mathbf{1}$ & 1 \\
$35-44$ & $0.94(0.75-1.19)$ & $1.06(0.75-$ \\
$25-34$ & $0.81(0.65-1.01)$ & $1.49)$ \\
$15-24$ & $0.79(0.58-1.08)$ & $1.00(0.66-$ \\
& & $1.52)$ \\
& & $0.94(0.50-$ \\
\hline
\end{tabular}

Bold = Significant at $p$-value $<0.05$, Primary model- Adjusted for factors with no missing data while secondary model adjusted for factors in primary model plus factors that had missing data. AOR: Adjusted odds ratio. COR: Crude Odds Ratio. 